\title{
Fazendo ou
}

\section{Desfazendo a União Europela enquanto Potência Global: Uma Análise sobre Potenciais Impactos da Turquia na Política Externa e de Segurança Comum do Bloco*}

\section{Paula Sandrin**}

Este artigo tem como objetivo desafiar a lógica binária que permeia a discussão sobre o impacto da adesão da Turquia na Política Externa e de Segurança Comum (PESC) da União Europeia (UE). Será defendido que qualquer análise sobre o impacto da adesão turca no papel da UE enquanto ator internacional precisa levar em consideração as divisões existentes dentro da Europa e dentro da Turquia no que diz respeito a discursos e práticas de segurança.

\footnotetext{
* Artigo recebido em 24 de fevereiro de 2015 e aprovado para publicação em 3 de março de 2015. ** Coordenadora do curso de graduação em Relações Internacionais da Pontifícia Universidade Católica do Rio de Janeiro (PUC-Rio), Rio de Janeiro, RJ, Brasil. E-mail: paulasandrin @ hotmail.com.
} 
A União Europeia e a Turquia não são atores monolíticos com entendimentos e preferências unitários. Faz-se necessário mapear as diferentes culturas de segurança que coexistem na União Europeia e na Turquia para então localizar onde o país se encontra no cenário mais amplo europeu. Um segundo objetivo deste artigo será fornecer indicações, que escapem a essa lógica binária, sobre o possível impacto da adesão turca no papel da UE enquanto ator global.

Com o intuito de ilustrar a pluralidade de culturas de segurança existentes na Europa e na Turquia e entender as potenciais contribuições do país para a Europa nas áreas de política externa e de segurança, serão analisadas as respostas da União Europeia como um bloco, de alguns países-membros europeus (França, Reino Unido e Alemanha) e da Turquia ao conflito na Líbia em 2011. Essa discussão nos permitirá identificar as diferenças e semelhanças nas percepções e preferências da UE, de alguns de seus países-membros e da Turquia em face de crises internacionais e nos ajudará a esclarecer as condições nas quais a Turquia está disposta a participar de ações internacionais do bloco.

O artigo será dividido em três partes seguidas por uma conclusão. Primeiramente será feita uma crítica à bibliografia que analisa o impacto potencial da Turquia nas políticas externa e de segurança da UE e na relevância da UE no cenário mundial. Essa literatura tende a retratar as possíveis contribuições da Turquia em termos drásticos: ou como um ativo que transformaria a UE em um ator internacional mais influente ou como um risco que potencialmente levaria à diluição do projeto europeu. Argumenta-se que é necessária uma abordagem mais matizada que não ignore as pluralidades internas da UE e da Turquia.

Na segunda seção, as premissas teóricas que pautam essa abordagem e a escolha metodológica serão esclarecidas. Será discutido, em particular, o conceito de cultura de segurança, e sua relação com identi- 
Fazendo ou Desfazendo a União Europeia enquanto Potência Global: Uma Análise...

dade e política externa. Como será observado na primeira seção, os termos cultura de segurança/estratégica, identidade de segurança (security identity), entendimentos de segurança e perspectivas de segurança tendem a ser utilizados de forma intercambiável. Dessa forma, na segunda parte, esses termos, seus significados e relações serão elucidados.

Na terceira seção, os discursos e políticas adotados em relação ao conflito na Líbia em 2011 por parte da UE como um todo, alguns países-membros europeus e pela Turquia serão recontados. Finalmente, após situar as culturas de segurança da Turquia no panorama europeu, concluiremos que é improvável que a adesão do país altere significativamente o papel da União Europeia no sistema internacional. Com ou sem a Turquia, a União Europeia deverá continuar a atuar como uma potência humanitária no cenário mundial. Dessa forma, os potenciais impactos da Turquia na política externa e de segurança da União Europeia não devem ser exagerados.

\section{Fazendo ou Desfazendo a União Europeia: A Turquia como Responsável pelo Êxito ou Fracasso do Bloco como Ator Global de Relevância}

Nas discussões concernentes à adesão da Turquia à União Europeia, muitos argumentos são avançados para defender ou combater a aceitação do país. O estado da economia turca, o tamanho de sua população (predominantemente muçulmana) e sua localização geográfica são utilizados como justificativas por aqueles que apoiam ou se opõem à adesão. Defensores argumentam que a população jovem, caráter muçulmano e laços com regiões vizinhas fariam da Turquia um grande ativo para a União Europeia. Opositores apontam para o baixo PIB per capita, fronteiras com alguns países do Oriente Médio, 
cultura supostamente não europeia e a possibilidade de um grande fluxo de imigrantes (um cenário bastante perturbador quando se considera discussões atuais sobre imigração e terrorismo islâmico em alguns Estados-membros) para sugerir que a Turquia não merece um lugar na Europa. Entre todos os argumentos a favor ou contra, a questão do potencial impacto da Turquia no papel da União Europeia no cenário mundial vem ganhando relevância.

Para um grupo de pessoas, que inclui defensores europeus e turcos da adesão, a Turquia contribuiria significativamente para o soft e o hard power do bloco. Os laços políticos, econômicos e culturais com os Bálcãs, Cáucaso, Oriente Médio e Ásia Central, a combinação entre Islã e democracia, a proximidade de fontes energéticas e suas capacidades militares seriam ativos para uma União Europeia que deseja aumentar sua influência no mundo. A Turquia já faz parte da arquitetura de segurança europeia por meio da OTAN, e durante a Guerra Fria ajudou a manter a estabilidade no sudeste europeu ao servir como um "baluarte" contra a expansão do poderio soviético (AYBET; MÜFTÜLER-BAÇ, 2000, p. 578).

A Turquia contribuiria para o soft power da União Europeia porque, ao aceitar um país muçulmano, a UE teria sua credibilidade e habilidade de projetar suas normas e valores para suas fronteiras meridionais reforçadas (MÜFTÜLER-BAÇ, 2009, p. 61). "O aval da Turquia ao posicionamento da União Europeia em questões mundiais traria legitimidade para o bloco aos olhos de não europeus" (MÜFTÜLER-BAÇ, 2009, p. 66). Além disso, a Turquia ajudaria a promover um entendimento entre as civilizações europeia e muçulmana (MÜFTÜLER-BAÇ, 2009, p. 65). Ademais, em outras regiões do mundo, como o Cáucaso e a Ásia Central, os laços linguísticos e culturais da Turquia seriam benéficos para o bloco. Em termos de hard power, a Turquia aumentaria a capacidade da UE de agir de forma autônoma (dos Estados Unidos), se tropas turcas (o segundo maior número da OTAN) fossem utilizadas em missões da União 
Fazendo ou Desfazendo a União Europeia enquanto Potência Global: Uma Análise...

Europeia. Em resumo, a Turquia aumentaria a credibilidade e a $c a-$ pacidade da União Europeia de agir em regiões próximas à Turquia.

Esse tipo de argumento é em geral feito por políticos turcos e europeus que são a favor da adesão. De acordo com o ex-ministro turco para Assuntos Europeus, Egemen Bagis, sem a Turquia, a União Europeia seria "uma irrelevante península ocidental no continente asiático" (BAGIS; MICHEL, 2011). Por meio do alargamento, a União Europeia poderia se expandir "não apenas geograficamente, mas também politicamente, economicamente, culturalmente e socialmente. $\mathrm{O}$ alargamento é um mecanismo que serve diretamente à emergência da UE como potência global" (BAGIS; MICHEL, 2011).

Argumentos similares foram apresentados em um relatório da Comissão Independente sobre a Turquia (2009), um grupo composto por ex-chefes de Estado, ministros das Relações Exteriores e comissários europeus presidido por Martti Ahtisaari, ex-presidente da Finlândia. Apesar de o relatório reconhecer que "a adesão de um país com o tamanho e características específicas da Turquia sem dúvida apresentaria à União Europeia desafios substantivos", ele prossegue dizendo que a "adesão de uma Turquia transformada, democrática e moderna, com uma posição geoestratégica única, um grande potencial econômico e uma força de trabalho jovem e dinâmica, traria consideráveis benefícios para a União Europeia". Os benefícios incluiriam a ajuda da Turquia para "administrar e assistir interesses europeus no Oriente Médio e em outros lugares" já que "uma Turquia empoderada pela União Europeia poderia adicionar a Europa como um player em uma região atualmente dominada pela Rússia, China e Estados Unidos" (COMISSÃO INDEPENDENTE SOBRE A TURQUIA, 2009, p. 29). O relatório acrescenta que "a Turquia não pode resolver qualquer crise ou problema por si só, mas, sem a Turquia, a tarefa da UE na região se torna uma luta penosa" (COMISSÃO INDEPENDENTE SOBRE A TURQUIA, 2009, p. 29). 
Por outro lado, oponentes da adesão turca argumentam que, em vez de ajudar a União Europeia a se tornar uma potência global, a Turquia, em função de seu tamanho e características específicas, iria colocar em risco o projeto político europeu, levando à sua diluição e transformando o bloco em um irrelevante mercado único.

Esse tipo de argumento está relacionado ao debate "alargamento x aprofundamento" e a discussões sobre a capacidade de absorção da União Europeia. É sustentado que o alargamento pode levar à diluição da UE: "não podemos prosseguir com alargamentos para sempre. Não podemos diluir o projeto político europeu e transformar a União Europeia em uma área de livre comércio de escala continental" (Romano Prodi apud EDWARDS, 2009, p. 53). Ademais, o histórico de relações problemáticas da Turquia com países vizinhos (Síria, Iraque, Irã, Armênia, Grécia e Chipre) seria "importado" pela UE. Assim, em vez de usar a Turquia como uma ponte para aproximar-se do Oriente Médio, a UE seria engolfada por conflitos nos quais não precisaria necessariamente se envolver (BUZAN; DIEZ, 1999).

Um terceiro tipo de argumento leva em consideração as diferentes culturas e identidades de segurança da Turquia e da União Europeia. Analistas como Buzan e Diez (1999), Bilgin (2004), Oguzlu (2002), Desai (2005), Ruacan (2007), Oguzlu e Kibaroglu (2008) e Ustun (2010) ressaltam que as diferentes percepções e práticas de segurança da Turquia e da União Europeia tornariam a Turquia um parceiro difícil na construção e consolidação de uma Política Externa e de Segurança Comum.

De acordo com essa literatura, os principais traços da cultura de segurança da União Europeia seriam: o reconhecimento de múltiplos objetos referentes de segurança e de novas ameaças, tendo, portanto, uma concepção ampla do conceito de segurança (BILGIN, 2004; OGUZLU, 2002; DESAI, 2005; OGUZLU; KIBAROGLU, 2008); 
Fazendo ou Desfazendo a União Europeia enquanto Potência Global: Uma Análise...

hesitação em securitizar questões e tendência a representar conflitos como questões políticas "normais" (BILGIN, 2004; OGUZLU; KIBAROGLU, 2008); a construção de uma comunidade de segurança, que não prevê o uso da força entre seus membros, por meio de um processo de integração (BUZAN; DIEZ, 1999; BILGIN, 2004; OGUZLU, 2002; DESAI, 2005; OGUZLU; KIBAROGLU, 2008); o fato de representar um modelo de relações entre Estados que vai significativamente além dos princípios de soberania e não intervenção (BUZAN; DIEZ, 1999); o fato de ser um ator internacional civil-normativo, (OGUZLU, 2002), um projeto pós-westfaliano (BUZAN; DIEZ, 1999; BILGIN, 2004) que em geral utiliza a cooperação para o desenvolvimento como meio de erradicar as causas de instabilidade e que prefere lidar com ameaças por meio de negociação, construção de consensos, engajamento e não contenção. Dessa forma, prefere empregar medidas de segurança "suaves" e meios civis (OGUZLU, 2002; DESAI, 2005; OGUZLU; KIBAROGLU, 2008; USTUN, 2010).

Já a Turquia teria como principais objetos referentes de segurança sua integridade territorial e a manutenção de um projeto de Estado-nação homogêneo (BILGIN, 2004; OGUZLU, 2002; DESAI, 2005); interpretaria muitas questões, internas e externas, sob a ótica da segurança, tendo uma cultura de segurança "realista", caracterizada por um determinismo geográfico - a ideia de que a Turquia está em uma localização geográfica "infeliz", em uma região instável, cercada por inimigos internos e externos, que, portanto, justificariam o uso de meios militares (BILGIN, 2004; DESAI, 2005); não estaria disposta a ceder soberania e teria pouca tolerância a interferências em sua esfera doméstica (BUZAN; DIEZ, 1999; USTUN, 2010).

Outras análises apontam modificações nos entendimentos e práticas de segurança da União Europeia e da Turquia e argumentam que as dicotomias apresentadas acima não mais se sustentam, já que estaria ocorrendo uma crescente convergência entre os dois em questões de 
segurança (HERD, 2009, p. 59). A Turquia estaria se tornando menos hobbesiana e a União Europeia menos kantiana (HERD, 2009, p. $60)$.

No caso da União Europeia, isso estaria ocorrendo em função de uma crescente militarização das respostas do bloco a conflitos externos e à securitização da migração. Manners (2006, p. 190), por exemplo, cita a Operação Artemis na República Democrática do Congo e a EUFOR Althea na Bósnia-Herzegovina como exemplos de missões nas quais a União Europeia priorizou objetivos militares em vez do reforço das capacidades dos países-alvo. As práticas e discursos de securitização da migração e da concessão de asilo por parte da UE e suas agências, como a FRONTEX, principalmente após o 11 de setembro, têm sido alvo de muitos estudos acadêmicos (LÉONARD, 2010; GUILD; BIGO, 2010; NEAL, 2009; HUYSMANS, 2006; BIGO, 2002, entre outros).

No caso da Turquia, a modificação dos discursos e práticas de segurança do país seria resultado de um processo de europeização da política externa turca desde que recebeu status de candidato em 1999 (AYDIN; ACIKMESE, 2007; OZCAN, 2008; ALTUNISIK, 2009), de processos mais gerais de dessecuritização (BILGIN, 2005; ARAS; POLAT, 2008; POLAT, 2010) ou da ascensão ao poder do partido Justiça e Desenvolvimento em 2002, com concepções identitárias e de segurança distintas (MURISON, 2006; DAVUTOGLU, 2010; KALIN, 2011). No entanto, o "abrandamento" das políticas interna e externa turcas e os laços que o país vinha construindo como parte da política de "zero problema com vizinhos" foram sendo progressivamente desgastados após a Primavera Árabe e em particular após a guerra civil na Síria. Discursos e práticas de securitização voltaram a ser observados, em relação a manifestantes do parque Gezi, curdos turcos e sírios, Israel ou Bashar al-Assad, levando a um questionamento sobre a profundidade das mudanças observadas na década anterior. 
Fazendo ou Desfazendo a União Europeia enquanto Potência Global: Uma Análise...

O principal problema das diferentes vertentes apresentadas acima é que todas insistem em tratar a Turquia e a União Europeia como atores monolíticos, sem contestações internas. Por exemplo, o argumento de que a Turquia reforçaria o poder brando e duro da União Europeia se sustenta em premissas questionáveis. A União Europeia terá mais credibilidade com o endosso turco de suas posições se a Turquia endossar as posições do bloco - o que não é algo que possa ser presumido, dado que a taxa de compatibilidade da Turquia às declarações da Política Externa e de Segurança Comum foi de apenas 46\% em 2013 (COMISSÃO EUROPEIA, 2013) - e se o bloco tiver uma posição comum. O caso da Líbia ilustrará como é difícil obter essa conjunção de fatores. A contribuição turca para o poder duro da União Europeia presume que esta gostaria de aumentar seu poderio militar, o que não é o posicionamento de todos os Estados-membros. Alguns países europeus são bastante relutantes em utilizar força fora de suas fronteiras e há divergências quanto à pertinência do uso de instrumentos militares para a solução de conflitos, como também ficará claro na discussão sobre o conflito na Líbia.

O argumento de que a Turquia colocará o "projeto político europeu" em perigo parte do princípio de que há um projeto político subscrito por todos os Estados-membros. No entanto, há projetos concorrentes para o futuro da União Europeia - de fortalecimento do supranacionalismo a um repatriamento de competências já cedidas para instâncias supranacionais; de uma União Europeia enquanto potência global que não reluta em utilizar poderio militar para perseguir seus interesses a uma potência humanitária que só utiliza força quando motivada por questões humanitárias, autorizada pelo direito internacional e em situações de baixo risco (MEYER, 2006). De forma que não fica claro porque a Turquia por si só causaria a diluição de um projeto mal definido que não é apoiado por todos os membros do bloco.

As análises que contrastam as culturas de segurança da União Europeia e da Turquia não levam em consideração as diferentes concep- 
ções de segurança operando dentro da União Europeia e dentro da Turquia. Essa literatura pressupõe que existe uma cultura de segurança europeia e ignora as diferentes concepções de segurança dos Estados-membros. No entanto, mesmo a literatura que trata da emergência de uma cultura de segurança/estratégica europeia (MEYER, 2006; KIRCHNER, 2010; BIAVA et al., 2011) considera que essa cultura emergente existe em paralelo às culturas de segurança dos Estados-membros, sem apagá-las. Além disso, a Turquia (assim como os países europeus) contém uma pluralidade de atores com percepções e preferências divergentes competindo por dominância. Ou seja, não se trata de atores monolíticos com percepções e preferências consensuais.

O argumento aqui avançado é que qualquer avaliação sobre o impacto da Turquia nas políticas externa e de segurança da União Europeia precisa levar em conta as contestações e divisões existente dentro da Turquia e da União Europeia. Do contrário, essa discussão continuará sendo permeada por uma lógica binária na qual os únicos impactos possíveis da adesão turca seriam fazer ou desfazer a UE.

\section{Identidade, Cultura de Segurança e Política Externa: Negociando Relações entre o Self e o Outro}

O conceito de cultura de segurança foi empregado pela primeira vez por Keith Krause, que o definiu como "crenças, tradições, atitudes e símbolos duradouros e amplamente partilhados que informam as maneiras através das quais interesses e valores estatais que dizem respeito à segurança, estabilidade e a paz são percebidos, articulados e promovidos por atores políticos e elites" (KRAUSE, 1999, p. 14). O termo é derivado do conceito de cultura estratégica, ${ }^{1}$ cunhado por Jack Snyder (1977), no relatório The Soviet Strategic Culture: Impli- 
Fazendo ou Desfazendo a União Europeia enquanto Potência Global: Uma Análise...

cations for Limited Nuclear Operations, no qual o autor argumentava que estrategistas soviéticos e americanos não eram puramente racionais, mas socializados em modos distintos de pensamento estratégico. Krause (1999) ampliou o conceito para incluir todos os aspectos da busca por segurança, para além do aspecto puramente militar, e desde então autores como Howorth (2002), Gariup (2009), Kirchner e Sperling (2010) e Ustun (2010) o vem empregando no estudo da União Europeia.

O conceito, apesar de amplamente utilizado, é controverso e, se mal empregado, pode tornar cultura algo essencial, primordial, fixo, estático, determinístico, unitário, homogêneo ou singular. Por exemplo, Gray (1999) faz referência aos "alemães", "britânicos", "russos", dando a entender que se trata de características compartilhadas por sociedades como um todo, não estando sujeitas a contestações internas ou a modificações ao longo do tempo.

No entanto, não há "identidades naturais ou originais, já que toda identidade é resultado de um processo contínuo [...] de hibridização e nomadização. Identidade é, efetivamente, resultado de uma multiplicidade de interações que ocorrem dentro de um espaço cujos contornos não são claramente definidos" (Mouffe apud NEUMANN, 1999, p. 210).

De fato, parte da literatura reconhece que culturas de segurança são construídas, negociadas, questionadas e modificadas. Berger (1998) argumenta que culturas de segurança não são mantidas por sociedades de forma unânime. Lapid (1996, p. 7) entende "identidade" e "cultura" como algo "socialmente construído, fragmentado, diverso e dinâmico", compartilhando "a percepção de multiplicidade" e "o tema onipresente da construção".

Em outras palavras, culturas de segurança e narrativas identitárias que as sustentam podem ser e são contestadas. Por exemplo, na Turquia, o sistema educacional republicano narrou uma visão da história 
(conspiratória e suspeita do Ocidente e do Oriente) e construiu um tipo de identidade (ocidental, secular e homogênea) que não foi amplamente aceita por todos os grupos da sociedade (como muçulmanos devotos, curdos e elites liberais).

Outra crítica ao conceito diz respeito à relação entre identidade, cultura de segurança e política externa. Hansen (2006, p. 2), por exemplo, tem reservas quanto a abordagens que consideram identidade como uma variável independente em uma relação causal com a política externa. Para a autora, identidade e política externa são coconstituídas. Tanto Hansen (2006) quanto Campbell (1998) argumentam que identidades são simultaneamente constituídas e reproduzidas por meio de formulações de política externa. Não é, portanto, possível separar identidade/cultura de política externa/práticas, pois não existe identidade anterior e independente de política externa (HANSEN, 2006, p. 26).

Contudo, dado que se trata de uma relação coconstituída, políticas externas dependem de representações de identidade (HANSEN, 2006, p. 1). "A identidade constitui a política externa e é produzida pela política externa" (HANSEN, 2006, p. 20, grifo meu). "Discursos políticos dependem de uma construção particular de problemas e subjetividades, mas problemas e subjetividades também são construídos por meio de discursos políticos" (HANSEN, 2006, p. 15, grifo meu). É possível, portanto, optar por uma análise de como identidades (construídas, instáveis e contestadas) influenciam a condução de política externa, sem estabelecer uma relação causal e unilateral entre os dois termos.

Consideradas as ressalvas acima, a relação entre identidade, cultura de segurança e política externa pode ser explicitada da seguinte forma: culturas de segurança resultam de interpretações de experiências históricas e sua propagação, o que ajuda a produzir ou a reproduzir identidades. Essas identidades são construídas em relação a uma sé- 
Fazendo ou Desfazendo a União Europeia enquanto Potência Global: Uma Análise...

rie de diferenças (WELDES et al., 1999), que podem ser articuladas de diferentes maneiras.

Nem todas as relações entre o self e o outro são antagônicas, ou seja, nem todos os outros são concebidos como radicalmente diferentes e existencialmente ameaçadores (WAEVER, 2001, p. 24). Podem existir outros concebidos como amigos e familiares, inferiores ou superiores, ou simplesmente diferentes, nem inferiores ou ameaçadores (DIEZ, 2005, p. 628). Consequentemente, a relação com o outro pode ou não envolver conflito. A política prescrita irá variar de acordo com a forma como o outro é concebido. Em outras palavras, há diferentes formas de lidar com a diferença: aniquilação, assimilação, transformação, apoio, isolamento, dissuasão, acomodação e terapia (HOPF, 2002; HANSEN, 2006). Se o outro é concebido como uma ameaça existencial por um ator securitizador e essa caracterização é aceita pela audiência, então é mais provável que as políticas empregadas para lidar com a ameaça sejam "excepcionais" na linguagem utilizada por Waever (1995). Se o outro é percebido como inferior, opções políticas prováveis incluem a provisão de "terapia" para "melhorar" o outro.

Por exemplo, em discursos europeus sobre a Turquia, o país é frequentemente descrito como um outro geográfico (por não estar na Europa/não compartilhar traços culturais europeus, como a religião) ou antiético (por não adotar valores europeus como respeito a minorias, por exemplo), mas também às vezes como temporalmente inferior, como um Estado moderno em oposição a uma Europa pós-moderna (como visto em Buzan e Diez (1999) acima).

Da mesma forma, podemos identificar na Turquia pelo menos duas culturas de segurança distintas, com concepções diferentes acerca da Europa e do Oriente Médio. Uma cultura de segurança que podemos chamar de republicana, calcada em uma concepção de identidade turca como ocidental, secular e homogênea, percebe a Europa de for- 
ma ambivalente, como ao mesmo tempo o "auge da civilização" que a Turquia deve emular e uma potencial ameaça que almeja enfraquecer e dividir a Turquia, que interfere em sua esfera doméstica, explora questões domésticas (como o problema curdo) e trata a Turquia de forma injusta. Nesse caso, o curso de ação preferido em relação à Europa é ganhar aceitação e reconhecimento como membro, para ter sua identidade ocidental confirmada, e resguardar ferozmente a soberania do país. Atores com essa concepção identitária apresentam o Oriente Médio como uma região atrasada e tomada por conflitos, em relação à qual a Turquia deve agir com cautela e evitar envolvimento. Já outra cultura de segurança que podemos chamar de neo-otomanista compartilha as mesmas suspeitas em relação à Europa, mas considera que o país já ocupa o mesmo patamar do continente e que, portanto, deve ser reconhecido como um igual por uma questão de prestígio. Essa cultura de segurança concebe o Oriente Médio como uma região com laços históricos e culturais com a Turquia, que seria o líder natural da região. Assim, o curso de ação preferido em relação à região vizinha é intenso envolvimento, o aprofundamento de laços políticos e econômicos e a gestão da região em um papel de liderança.

Assim, a cultura de segurança condiciona os objetivos básicos de política externa que devem ser assegurados (e que refletem uma construção identitária particular com as correspondentes concepções dos "outros"); condiciona as opções de políticas que são consideradas aceitáveis, legítimas e apropriadas; influencia a avaliação dessas opções; e, portanto, ajuda a moldar escolhas de políticas externa e de segurança (DUFFIELD, 1999, p. 771).

Na próxima seção, analisaremos as respostas da Turquia, França, Reino Unido, Alemanha e União Europeia enquanto bloco ao conflito na Líbia em 2011 com o objetivo de ilustrar a diversidade de culturas de segurança existentes e questionar narrativas sobre a potencial contribuição turca às políticas externa e de segurança que se pautam 
Fazendo ou Desfazendo a União Europeia enquanto Potência Global: Uma Análise...

nas percepções monolíticas da Turquia e da União Europeia. Aqui cabe uma ressalva: a escolha de apenas três países-membros europeus se deu por questões pragmáticas. Não seria possível acompanhar as discussões de todos os então 27 países-membros. Assim, o foco será nos três países tradicionalmente considerados mais influentes.

A análise será baseada em discursos de representantes da União Europeia envolvidos no processo decisório em política externa, de atores políticos de países-membros (França, Reino Unido e Alemanha) e da Turquia, e em entrevistas realizadas com atores políticos turcos e europeus. $^{2}$

Essa análise é baseada na proposta de Hansen (2006, p. 28) de mapear debates sobre política externa ao redor de eventos-chave da agenda política e midiática. Por meio dessa investigação, será possível mapear diferentes percepções e consequentes respostas ao conflito; situar a localização da Turquia em meio à diversidade de culturas de segurança europeias; e prover algumas indicações sobre o potencial impacto do país nas políticas externas e de segurança da União Europeia.

\section{A Crise na Líbia em 2011 - Percepções e Respostas Plurais}

Os levantes na Líbia começaram no dia 17 de fevereiro de 2011, inspirados pelos protestos na Tunísia e no Egito. O ditador líbio Muammar Gaddafi respondeu aos protestos com o uso de força mortal.

A União Europeia ficou dividida em relação a como responder à repressão de Gaddafi à população. A França e o Reino Unido manifestaram preferência por uma resposta militar, ao passo que a Alemanha preferiu uma resposta política. A Alemanha não participou da opera- 
ção militar que impôs uma zona de exclusão aérea e que conduziu ataques aéreos contra as forças de Gaddafi, e se absteve na votação do Conselho de Segurança que autorizou a operação (Resolução 1973). Em função dessa divisão, a União Europeia não pôde fazer mais do que emitir declarações, aplicar sanções e sugerir a criação de uma missão (EUFOR Líbia), que nunca saiu do papel. Já a Turquia inverteu completamente sua posição durante o curso dos eventos: primeiramente se opôs duramente a qualquer tipo de intervenção militar, mas depois decidiu participar da operação da OTAN.

No dia 20 de fevereiro, a então alta representante para Assuntos Exteriores e Política de Segurança, Catherine Ashton, emitiu uma declaração em nome da União Europeia alegando que o bloco estava "extremamente preocupado com os eventos em curso na Líbia" (CONSELHO DA UNIÃO EUROPEIA, 2011a) e incitando as autoridades líbias a não usar violência. O bloco então implementou sanções ainda mais rígidas contra a Líbia do que as autorizadas pela Resolução 1970 do Conselho de Segurança da ONU de 26 de fevereiro. No dia 28 de fevereiro, o Conselho de Ministros adotou a decisão 2011/137/CFSP, impondo um embargo de armas contra a Líbia e sanções direcionadas, incluindo proibições de vistos e congelamento de bens de pessoas envolvidas com o regime de Gaddafi (CONSELHO DA UNIÃO EUROPEIA, 2011b).

Cerca de dez dias após o início dos confrontos, o primeiro-ministro britânico, David Cameron, anunciou que estava trabalhando com os seus aliados em planos para estabelecer uma zona de exclusão aérea na Líbia (CAMERON..., 2011). O ministro da Defesa britânico anunciou que, naquele momento, os planos ainda estavam em fase inicial, e o foco era em que países apoiariam o plano e que tipo de capacidade militar seria necessária (CAMERON..., 2011). O então ministro de Negócios Estrangeiros, William Hague, exigiu o fim imediato da violência contra os manifestantes: "esse é um aviso para qualquer um contemplando o abuso de direitos humanos na Líbia ou 
Fazendo ou Desfazendo a União Europeia enquanto Potência Global: Uma Análise...

em qualquer outro país. Haverá um dia de cômputo e o alcance da justiça internacional é longo. Nós precisamos [...] garantir que não haja impunidade para os crimes cometidos na Líbia" (CAMERON..., 2011).

O primeiro-ministro britânico também anunciou que estava tomando "todas as medidas necessárias para isolar o regime de Gaddafi", tendo congelado os bens em solo britânico de Gaddafi e sua família, retirado sua imunidade diplomática, proibido a exportação de cédulas da moeda líbia, impressas no Reino Unido, e cooperado com outros membros da União Europeia na aplicação de sanções (CAMERON..., 2011).

A Turquia declarou que era contra o estabelecimento de sanções, com o argumento de que quem sofreria em consequência seria a população e não os líderes do país. Também acusou a comunidade internacional de estar agindo por conta de interesses econômicos, e não em função de uma perspectiva humanitária (IDIZ, 2011). O primeiro-ministro turco, Recep Erdogan, ainda afirmou que a OTAN não deveria ser utilizada para distribuir os recursos da Líbia entre certos países e que uma intervenção da OTAN na Líbia seria "absurda" (YINANÇ, 2011).

No dia 8 de março, a França e o Reino Unido anunciaram que estavam elaborando uma resolução da ONU estabelecendo uma zona de exclusão aérea na Líbia e que o assunto seria discutido pela OTAN no dia 10 de março. O ministro das Relações Exteriores britânico, William Hague, fez questão de frisar que a zona de exclusão aérea só seria implementada se houvesse apoio de países árabes e africanos e uma resolução da ONU aprovando o plano (LIBYA..., 2011a). Naquele momento, os países do Golfo se declararam a favor de uma zona de exclusão aérea e marcaram uma reunião de emergência da Liga Árabe para o dia 12 de março (LIBYA..., 2011a). 
O entusiasmo da França e do Reino Unido para estabelecer uma zona de exclusão aérea não era compartilhado por todos os líderes europeus. Em uma reunião de ministros das Relações Exteriores europeus em Bruxelas no dia 9 de março, o ministro alemão, Guido Westerwelle, disse que era preciso "ter cuidado para não se envolver em um conflito militar que poderia vir a ser de longa duração e para não tomar partido em algo que poderia se tornar uma guerra civil" (CASERT, 2011). Na mesma reunião, os ministros europeus concordaram em endurecer as sanções contra o regime líbio e prover mais ajuda humanitária.

Em uma reunião de cúpula dois dias depois (11 de março), as esperanças do Reino Unido de incluir uma referência explícita à OTAN e ao estabelecimento de uma zona de exclusão aérea na declaração final do encontro foram efetivamente frustradas. A chanceler alemã, Angela Merkel, notou que não havia base legal para o estabelecimento de uma zona de exclusão aérea, e a alta representante Catherine Ashton afirmou que eram grandes os riscos de baixas civis e danos colaterais e que a eficiência de uma zona de exclusão aérea era "questionável" (TRAYNOR, 2011).

Os chefes de Estado na reunião de cúpula declararam que Gaddafi havia perdido toda a legitimidade como interlocutor e o exortaram a renunciar. Também saudaram e encorajaram o Conselho de Transição Nacional, que, apesar de não ter sido reconhecido como o único representante da Líbia, foi considerado um "interlocutor político" (CONSELHO DA UNIÃO EUROPEIA, 2011c). A declaração final alertava que, "com o intuito de proteger civis, Estados-membros irão examinar todas as opções necessárias, desde que haja necessidade comprovada, uma base legal clara e apoio da região" (CONSELHO EUROPEU, 2011). David Cameron notou que "todas as opções necessárias era uma expressão forte", mas também esclareceu que "a União Europeia não é uma aliança militar e eu não quero que seja uma aliança militar. Nossa aliança militar é a OTAN" (TRAYNOR, 
Fazendo ou Desfazendo a União Europeia enquanto Potência Global: Uma Análise...

2011). O então presidente francês, Nicolas Sarkozy, irritado com a oposição da Alemanha, afirmou que "nós e os britânicos estamos pensando sobre o que deve ser feito quando civis pacíficos são alvos de tiros sendo disparados por helicópteros e aviões de guerra. David Cameron e eu pensamos: deveríamos apenas olhar e não fazer nada quando civis estão sendo massacrados?" (TRAYNOR, 2011).

A França e o Reino Unido mais uma vez tentaram obter apoio para a zona de exclusão aérea na Líbia alguns dias depois em uma reunião de ministros das Relações Exteriores do G8 em 14 de março, mas novamente foram frustrados pela oposição da Alemanha. Guido Westerwelle disse após o encontro: "nós somos muito céticos em relação a intervenções militares, e uma zona de exclusão aérea é uma intervenção militar" (FRANCE..., 2011). Enquanto isso, a União Europeia enviou uma missão de dois dias para a cidade rebelde de Benghazi para "coletar informação e avaliar a situação para apoiar um planejamento prudente em resposta à crise na Líbia" (FRANCE..., 2011).

No dia 17 de março, a resolução 1973, finalmente estabelecendo uma zona de exclusão aérea sobre a Líbia, foi aprovada pelo Conselho de Segurança da ONU. França, Reino Unido, Estados Unidos e sete outros membros não permanentes do Conselho de Segurança votaram a favor da resolução, e China, Rússia, Alemanha, Brasil e Índia se abstiveram (LIBYA..., 2011b). A Resolução 1973 determinou que "a situação na Líbia continua a constituir uma ameaça para a paz e a segurança internacionais" e, em conformidade com o "capítulo VII da Carta", "autoriza os Estados-membros [...] a tomar todas as medidas necessárias para proteger os civis sob a ameaça de ataque na Líbia, incluindo Benghazi, excluindo uma ocupação estrangeira de qualquer forma em qualquer parte do território da Líbia", e "decide estabelecer uma proibição de todos os voos no espaço aéreo da Líbia a fim de ajudar e proteger os civis", excetuando apenas aqueles "cuja única finalidade é humanitária - como para entrega ou facilitação da 
prestação de assistência, incluindo suprimentos médicos, alimentação ou agentes humanitários" (CONSELHO DE SEGURANÇA DAS NAÇÕES UNIDAS, 2011). A votação foi precedida por um pedido da Liga Árabe ao Conselho de Segurança para o estabelecimento da zona de exclusão aérea, evidência de um crescente apoio regional para a ação.

É importante ressaltar que a decisão da Alemanha de se abster foi bastante criticada por alguns atores políticos alemães. O ex-ministro das Relações Exteriores Joschka Fischer disse que "a Alemanha tinha perdido toda a credibilidade na ONU e no Oriente Médio" e que "as esperanças de um assento permanente no Conselho de Segurança haviam sido permanentemente perdidas e que agora ele temia pelo futuro da Europa" (FISCHER..., 2012). Além disso, Fisher disse que o comportamento do governo alemão durante a crise na Líbia era a pior atitude em termos de política externa do país desde a fundação da República Federal da Alemanha e que a posição do país no mundo havia sido significativamente prejudicada (BERLIN..., 2011). O chefe das forças armadas alemães disse que o país havia "tornado a ideia de uma política externa europeia unificada uma piada" e que a oposição à França rompia com toda a experiência alemã em política externa desde 1949. De acordo com ele, o legado de [Konrad] Adenauer e [Helmut] Kohl - e de todos os chanceleres alemães - era de que a Alemanha nunca mais deveria se ver isolada e que agora o país estava isolado em função de um vago risco de se envolver em uma guerra na África (Klaus Naumann apud FISCHER..., 2012).

Já Guido Westerwelle defendeu o governo alemão dizendo:

Nós queremos parar o ditador. Desde o começo nós lideramos esforços internacionais e europeus para impor sanções. Mas missões militares e bombardeios aéreos são outra coisa. Nós não queremos iniciar um processo que poderia terminar com tropas alemães participando de 
Fazendo ou Desfazendo a União Europeia enquanto Potência Global: Uma Análise...

uma guerra na Líbia. No que tange a operações militares, eu faço parte de uma tradição de comedimento. O mais importante é proteger pessoas e prover ajuda humanitária (GADDAFI..., 2011).

No dia em que a resolução 1973 foi adotada, a Turquia recebeu representantes do Conselho Nacional de Transição e declarou estar participando de intensas negociações com as duas partes do conflito. $\mathrm{O}$ ministro das Relações Exteriores turco, Ahmet Davutoglu, declarou que: "nós exercemos nossos melhores esforços para resolver a situação na Líbia usando instrumentos diplomáticos. Talvez nossos esforços não tenham sido totalmente compreendidos, mas a história irá confirmar como a Turquia agiu de forma responsável e tratou a Líbia de forma amistosa" (TURKEY..., 2011).

Dois dias após a aprovação da resolução, líderes da Europa, Estados Unidos e Oriente Médio foram convidados para uma reunião de emergência em Paris a fim de discutir os próximos passos necessários à implementação da zona de exclusão aérea. Líderes dos EUA, Reino Unido, Canadá, Alemanha, Noruega, Itália, Dinamarca, Bélgica, Espanha, Polônia, Catar, Marrocos, Emirados Árabes Unidos, Liga Árabe, União Europeia, e o secretário-geral da ONU foram convidados (KIRKPATRICK et al., 2011). Com a notícia de que as forças de Gaddafi estavam atacando a cidade rebelde de Benghazi, aviões de guerra franceses iniciaram a operação, antes mesmo do término da reunião em Paris.

A Turquia, que não foi convidada para a reunião, e continuava a se opor a qualquer tipo de intervenção militar, declarou-se contra a liderança da França. Em uma entrevista, ${ }^{3}$ um assessor especial do ministro das Relações Exteriores turco perguntou: "Os franceses são os donos das Nações Unidas? Não. São os donos da União Europeia? Não. São os donos da OTAN? Não. Onde eles conseguiram obter autoridade para conduzir esse tipo de operação?" Ele afirmou ainda que 
Hillary Clinton havia manifestado surpresa com a ausência da Turquia na reunião em Paris.

Críticas à França foram expressas por outros atores políticos turcos. O então ministro da Defesa, Vecdi Gönül, declarou ser "impossível entender a proeminência da França nesse processo. Temos dificuldades em entender porque a França está agindo como executor de decisões das Nações Unidas" (TURKEY ..., 2011). O então ministro para Assuntos Europeus, Egemen Bagis, foi ainda mais longe e acusou o presidente francês Nicolas Sarkozy de ter iniciado sua campanha de reeleição ao organizar um encontro que levou a bombardeios aéreos na Líbia: "Sarkozy agiu antes de uma decisão da OTAN, e seu ato foi baseado em uma avaliação subjetiva de uma resolução da ONU" (WATT et al., 2011).

O ministro das Relações Exteriores, Ahmet Davutoglu, acrescentou que, "antes de tudo, existe um procedimento no direito internacional para a formação de uma coalizão desse tipo. Não temos convicção de que esse procedimento tenha sido seguido. Nós informamos ao [ministro de Negócios Estrangeiros britânico] William Hague e à [secretária de Estado] Hillary Clinton que achamos inapropriado a operação - que deveria estar sob a governança das Nações Unidas, dentro dos parâmetros de princípios fundamentais da ONU e aberta à participação - ter sido lançada em um reunião composta por um pequeno grupo de países" (TURKEY..., 2011, grifo meu).

No início, houve confusão em relação a quem estava liderando a operação, já que a França, o Reino Unido e os Estados Unidos lideravam suas próprias operações. O ministro da Defesa francês afirmou que os Estados Unidos eram o "principal coordenador", mas não o comandante; e os Estados Unidos declararam que queriam deixar a OTAN a cargo da manutenção da zona de exclusão aérea e do embargo de armas, uma opção inicialmente rejeitada pela França (ERLANGER, 2011). 
Fazendo ou Desfazendo a União Europeia enquanto Potência Global: Uma Análise...

De acordo com o ministro das Relações Exteriores francês, "a Liga Árabe não quer que a operação esteja sob total responsabilidade da OTAN. Não foi a OTAN que tomou a iniciativa até agora [...] trata-se de uma coalizão com a participação de países árabes, norte-americanos e europeus" (ERLANGER, 2011). O Reino Unido, no entanto, concordava com os Estados Unidos. O primeiro-ministro explicou ao Parlamento britânico que: "atualmente a coalizão está operando sob comando dos Estados Unidos com a intenção de ser transferida para a OTAN" (David Cameron apud ERLANGER, 2011).

A Turquia também se declarou contra a transferência do comando da operação para a OTAN. De acordo com o primeiro-ministro Recep Erdogan: "uma intervenção militar da OTAN na Líbia ou em qualquer outro país seria totalmente contraproducente [...] e teria consequências perigosas" (FISCHER..., 2012). Portanto, ironicamente, a Turquia e a França, antes em campos opostos, agora lideravam conjuntamente a oposição à transferência do comando da operação para a OTAN.

Após um encontro de quarto dias entre membros da OTAN em Bruxelas, e ligações telefônicas do presidente Obama para Nicolas Sarkozy e Recep Erdogan, e entre Hillary Clinton, William Hague, Alain Juppé e Ahmet Davutoglu, França e Turquia finalmente concordaram com a transferência do comando militar do dia a dia da zona de exclusão aérea para a OTAN, enquanto o comando político continuou sob responsabilidade de uma coalizão internacional que incluía países árabes como Catar e Emirados Árabes Unidos (WATT et al., 2011). O fato de a supervisão política ficar a cargo de uma coalizão internacional, e não da OTAN, foi retratado como uma vitória política por Sarkozy. Ao mesmo tempo, a participação da OTAN foi uma derrota para a França, que não desejava o envolvimento da aliança no conflito (WATT et al., 2011). 
Apenas cinco dias após o início da operação, a Turquia abandonou por completo sua oposição e passou a fazer parte da operação, controlando o aeroporto de Benghazi e assim coordenando a entrega de ajuda humanitária, enviando cinco navios e um submarino para ajudar a fiscalizar o embargo de armas, e impondo sanções contra o regime líbio. A base aérea de Izmir, na Turquia, também passou a funcionar como o centro de comando da operação (TURKISH..., 2011).

Fontes do governo explicaram a mudança de posição dizendo que o país revisou sua postura após a autorização do Conselho de Segurança e a demonstração de apoio à operação pela Liga Árabe. No entanto, como exposto acima, mesmo após o início dos bombardeios, a Turquia continuou a expressar seu descontentamento. Outra explicação plausível seria que, após se dar conta de que a operação iria de fato prosseguir, a Turquia não queria se manter excluída. Passou então a insistir que a OTAN, e não a França, liderasse os esforços. De fato, depois de descartar seu veto ao envolvimento da OTAN, a Turquia passou a desempenhar um papel crucial, já que o centro de comando da operação estava em seu território. O primeiro-ministro Erdogan chegou a anunciar que a decisão de colocar a operação sob comando da OTAN e de utilizar a base aérea de Izmir como o centro de comando era um "desenvolvimento positivo" e que Paris "havia começado a ser excluída” (TURKISH..., 2011).

O principal partido de oposição na Turquia, o Partido Republicano do Povo, votou a favor da autorização requisitada pelo governo à Assembleia Nacional para participar da missão da OTAN. No entanto, o partido criticou a primeira posição adotada pelo governo. De acordo com o vice-líder do partido, Osman Koruturk (2011), “o Justiça e Desenvolvimento não deveria ter se oposto à intervenção da OTAN, mas discutido a questão dentro da OTAN - como um membro da OTAN - com o intuito de influenciar a política da aliança em relação à Líbia". 
Fazendo ou Desfazendo a União Europeia enquanto Potência Global: Uma Análise...

A Turquia continuou seus esforços para obter uma solução negociada ao apresentar um plano que incluiria o recuo das forças de Gaddafi de cidades sitiadas, o estabelecimento de corredores humanitários e uma transição democrática (KART, 2011; ERDOGAN..., 2011, p. 4). Quando nenhum dos dois lados do conflito deu atenção ao plano turco, o país passou a concordar com a posição da França, Reino Unido e Estados Unidos de que Gaddafi deveria renunciar (ERDOGAN..., 2011a, p. 4).

O ministro Davutoglu explicou que, "quando Gaddafi não nos escutou, deixamos nossa posição clara: você precisa ir embora porque não nos escutou" (AL-JAZEERA, 2011). O embaixador turco em Trípoli foi convocado e Davutoglu visitou Benghazi, onde foi recebido por rebeldes na praça Tahrir sem colete à prova de balas e disse, em árabe: "Eu trago cumprimentos do povo turco [...] nós temos uma história comum e um futuro comum." As multidões gritavam "Obrigado, Turquia" e "Erdogan, Turquia, Muçulmana" (OZERKAN, 2011). Finalmente, depois que Gadaffi abandonou Trípoli, Erdogan visitou a Líbia um dia após a visita de David Cameron e Nicolas Sarkozy. Essa visita demonstra simbolicamente os esforços por parte de determinados atores turcos - aqueles com uma cultura de segurança neo-otomanista - de ter o país reconhecido como igual por países europeus e de se tornar um líder no Oriente Médio e Norte da África (regiões que constituíram o Império Otomano).

No dia $1^{\underline{0}}$ de abril, o Conselho de Ministros da União Europeia aprovou a decisão de estabelecer a EUFOR Líbia, uma operação militar com mil tropas, cujo objetivo seria garantir a segurança de corredores marítimos e terrestres para a entrega de ajuda humanitária, caso fosse requisitado pelo OCHA (Escritório das Nações Unidas para a Coordenação de Assuntos Humanitários). No entanto, o OCHA argumentou que a missão poderia colocar em risco a vida da equipe de ajuda, ao associá-la com atores militares, e a missão foi permanentemente abortada (PHILIPS, 2011). Já em maio de 2013, o Conselho 
de Ministros aprovou a missão EUBAM Líbia, uma missão civil, solicitada pelo próprio governo líbio, com 110 especialistas que ajudam autoridades do país a melhorar a segurança das fronteiras.

O papel limitado da União Europeia na crise da Líbia pode ser explicado pela relutância de alguns Estados-membros em utilizar força militar fora de suas fronteiras. De acordo com um diplomata europeu, "alguns Estados-membros não eram a favor de uma operação da PESC [...] o único resultado possível foi um papel mínimo para a União Europeia" (apud KOENIG, 2011, p. 11). A Alemanha, como já vimos, se absteve da votação no Conselho de Segurança que autorizou a zona de exclusão aérea. Ademais, a Suécia bloqueou a adoção do conceito de operações para a EUFOR Líbia em uma reunião do Conselho de Negócios Estrangeiros do Conselho de Ministros no dia 12 de abril de 2011 porque o país era a nação-quadro de um dos dois agrupamentos táticos em stand-by, cuja mobilização estava sendo considerada no contexto da EUFOR Líbia (KOENIG 2011, p. 11).

O presidente francês Nicolas Sarkozy avaliou a intervenção na Líbia como uma lição para a política externa europeia, porque, segundo ele, pela primeira vez, "os europeus demonstraram ser capazes de intervir de uma forma decisiva, com seus aliados, em um conflito em suas fronteiras" e que isso significava que, no futuro, a Europa desempenharia um papel mais importante na segurança do Oriente Médio e do Norte da África vis-à-vis os Estados Unidos (RETTMAN, 2011).

No entanto, como notado por um funcionário da Comissão Europeia, ${ }^{4}$ "foram os franceses e britânicos que agiram e não a União Europeia por meio da PESC".

Essa exposição das respostas ao conflito na Líbia deve deixar claro que a União Europeia e a Turquia não são atores monolíticos com culturas de segurança que possam ser contrastadas, como o faz parte de literatura analisada na primeira seção. 
Fazendo ou Desfazendo a União Europeia enquanto Potência Global: Uma Análise...

$\mathrm{Na}$ União Europeia, existem diferentes percepções e consequentes preferências de cursos de ação frente a crises internacionais. Não existe uma única cultura de segurança europeia.

A França e o Reino Unido consideram que tem papéis relevantes a desempenhar na solução de conflitos mundiais e valorizam o uso da força para atingir seus objetivos. É notável que o Reino Unido tenha sugerido o estabelecimento de uma zona de exclusão aérea apenas dez dias após o início dos confrontos. No entanto, o Reino Unido prioriza sua parceria com os Estados Unidos via OTAN, em detrimento de ações por meio da União Europeia. Já a França prefere uma União Europeia mais autônoma, o que explica a relutância de Paris em transferir o comando da operação para a OTAN e a tentativa de Sarkozy de apresentar a missão como conduzida por "europeus", quando os Estados Unidos desempenharam um papel crucial.

Já a Alemanha, apesar da oposição interna sofrida pelo governo, reluta para usar poderio militar fora de suas fronteiras. O caso da Alemanha também é interessante porque demonstra que culturas de segurança não são unânimes e estão sempre sujeitas a contestações. Por restrição de espaço, não pudemos fazer o mesmo exercício para o Reino Unido e para a França, mas o argumento se sustenta nesses dois casos também.

Já a Turquia possui pelo menos duas culturas de segurança. A neo-otomanista é caracterizada por um senso de responsabilidade e conexão em relação a regiões que foram parte do Império Otomano, e líderes turcos anseiam por um papel de liderança nessas áreas. Além disso, desejam que o país seja reconhecido como um ator relevante no Oriente Médio, cuja opinião deve ser levada em consideração, e como um parceiro em pé de igualdade com a Europa. Esses dois desejos explicam a irritação de atores políticos turcos ao não serem convidados para a reunião de Paris e o desconforto de serem deixados de fora da operação, uma vez que ficou claro que não haveria 
um curso de ação alternativo. A Turquia passou então a insistir que a operação fosse comandada pelo OTAN, onde a Turquia poderia expressar suas opiniões.

A cultura de segurança republicana, como vimos, preza pelos laços com a Europa, e assim recriminou o governo turco por ter se oposto tão ferrenhamente à ação da OTAN, e logo aprovou o pedido de autorização para participar da operação enviada pelo governo ao parlamento.

\section{Conclusão}

Este artigo procurou demonstrar que, para avaliar o possível impacto da adesão turca nas políticas externa e de segurança da União Europeia, é preciso levar em consideração as divisões existentes na Turquia e na União Europeia em termos de culturas de segurança. Do contrário, os efeitos da adesão da Turquia serão expostos em termos drásticos, e o país será representado como o responsável pelo êxito ou fracasso do projeto europeu.

Conclui-se que, dadas as divisões já existentes dentro da União Europeia, e os traços das culturas de segurança turcas, é pouco provável que a adesão do país afetará de forma significativa o papel desempenhado pela UE no mundo. Em outras palavras, as proposições de que a Turquia ajudaria a União Europeia a se tornar uma potência global e que o país poderia diluir a UE a tal ponto que o projeto político europeu seria abandonado são exageradas. Com ou sem a Turquia, a União Europeia deve continuar a agir como uma potência humanitária no cenário mundial, preferindo utilizar meios civis e usando força militar somente quando autorizado pelo Conselho de Segurança da ONU, em situações de baixo risco, com objetivos humanitários (MEYER, 2006, p. 30). 
Fazendo ou Desfazendo a União Europeia enquanto Potência Global: Uma Análise...

Essas preferências da União Europeia não refletem uma identidade ou cultura de segurança singular do bloco, mas um processo decisório caracterizado pela necessidade de unanimidade entre atores com percepções e preferências diversas. A União Europeia não é uma potência global, mesmo sem a Turquia, porque não há consenso entre países-membros de que esse é um projeto desejável. Em outras palavras, a União Europeia age da forma como lhe é permitido por seus países-membros. A Turquia só tornaria esse cenário ainda mais plural.

Discutiu-se também que ambas as culturas de segurança da Turquia almejam o reconhecimento do país por parte da Europa, seja para ter sua identidade ocidental confirmada (no caso da cultura de segurança republicana) ou para ser reconhecida como uma potência em pé de igualdade por questões de prestígio (no caso da neo-otomanista). O país historicamente se dispôs a participar de operações multilaterais de apoio à paz, sejam elas realizadas pela ONU, OTAN ou União Europeia, desde que a Turquia possa participar do processo decisório. Mesmo tendo sido excluída das estruturas institucionais que decidem operações europeias após a criação da Política Comum de Segurança e Defesa (PCSD), ${ }^{5}$ a Turquia participa de várias missões. De fato, a Turquia é o país não membro da UE que mais contribui para operações da PCSD, tendo participado, por exemplo, da EUFOR Althea e EUPM na Bósnia-Herzegovina, Concordia e EUPOL na Macedônia, EULEX no Kosovo e EUNAVFOR Atalanta na costa da Somália (BLOCKMANS, 2010, p. 16; MÜFTÜLER-BAÇ, 2009, p. 69). Assim, a Turquia já contribui para a União Europeia enquanto potência humanitária.

A discussão feita aqui traz duas importantes implicações. A primeira é que a Turquia não deve ser excluída da União Europeia com base em medos superestimados das consequências da adesão turca no papel da União Europeia no mundo. Um segundo desdobramento im- 
portante é que a Turquia tenderá a agir de forma mais cooperativa se for consultada e tratada como igual e como uma potência regional.

\section{Notas}

1. Depois de Snyder, outros autores, como Booth (1979), Gray (1986; 2007), Johnston (1996, 1999), Lantis (2002), Neumann e Heikka (2005), continuaram a empregar o conceito para analisar diferentes países.

2. Foram conduzidas entrevistas com atores políticos da Turquia do partido governista Justiça e Desenvolvimento e do principal partido de oposição, Partido Republicano do Povo; diplomatas do Ministério das Relações Exteriores da Turquia; e representantes da União Europeia e de países-membros que trabalham no Serviço de Ação Externa Europeu e no Comitê de Representantes Permanentes do Conselho de Ministros. Ao todo, foram realizadas quatorze entrevistas entre 2011 e 2012.

3. Entrevista conduzida em Ancara em 2 de maio de 2011.

4. Entrevista conduzida em Bruxelas em 9 de outubro de 2012.

5. Antes da transferência das tarefas e instituições da União da Europa Ocidental (UEO) para a PCSD, a Turquia, como membro associado da UEO, era capaz de exercer uma influência considerável, já que podia submeter propostas, participar de grupos de trabalho e expressar suas opiniões e ressalvas antes que qualquer decisão fosse tomada (BLOCKMANS, 2010, p. 5). Com a criação da PSDC, a Turquia foi excluída do processo decisório.

\section{Referências Bibliográficas}

AL-JAZEERA. The New Ottomans. Empire television program, 16 jun. 2011. Transcrição disponível em: <http://english.aljazeera.net/programmes/empire/ 2011/06/201162810217630746.html>. Acesso em: 6 out. 2011. 
Fazendo ou Desfazendo a União Europeia enquanto Potência Global: Uma Análise...

ALTUNISIK, Meliha. Turkey-EU Relations: Creating New Synergies in the Middle East. In: COMELLI, M.; ERALP, A.; USTUN, Ç. (Org.). The European Neighborhood Policy and the Southern Mediterranean. Ancara: Middle East Technical University Press, 2009.

ARAS, Bulent; POLAT, Rabia Karakaya. From Conflict to Cooperation: Desecuritization of Turkey's Relations with Syria and Iran. Security Dialogue, n. 39, p. 495-515, 2008.

AYBET, Gulnur; MÜFTÜLER-BAÇ, Meltem. Transformations in Security and Identity after the Cold War: Turkey's Problematic Relationship with Europe. International Journal, v. 55, n. 4, p. 567-582, 2000.

AYDIN, Mustafa; ACIKMESE, Sinem A. Europeanization through EU Conditionality: Understanding the New Era in Turkish Foreign Policy. Balkan and Near Eastern Studies, v. 9, n. 3, p. 263-274, 2007.

BAGIS, Egemen; MICHEL, Louis. Turkey and EU Membership: A Win-Win Situation. EU Observer, 12 dez. 2011. Disponível em: <http://euobserver. com/7/114603>. Acesso em: 13 dez. 2011.

BERGER, Thomas U. Cultures of Antimilitarism: National Security in Germany and Japan. Londres: Johns Hopkins University Press, 1998.

BERLIN Has Lost Touch with Reality. Spiegel Online, 29 ago. 2011. Disponível em: <http://www.spiegel.de/international/germany/ex-foreign-ministerfischer-berlin-has-lost-touch-with-reality-a-783043.html>. Acesso em: 9 nov. 2012.

BIAVA, Alessia; DRENT, Margriet; HERD, Graeme P. Characterizing the European Union's Strategic Culture: An Analytical Framework. Journal of Common Market Studies, v. 49, n. 6, p. 1.227-1.248, 2011.

BIGO, D. Security and Immigration: Toward a Critique of the Governmentality of Unease. Alternatives, n. 27, p. 63-92, 2002.

BILGIN, Pinar. Clash of Cultures? Differences between Turkey and the European Union on Security. In: KARAOSMANOGLU, A.; SEYFI, T. (Org.). The Europeanization of Turkey's Security Policy: Prospects and Pitfalls. Ancara: Foreign Policy Institute, 2004.

Changing Security Discourses: The Challenge of Globalisation. European Journal of Political Research, v. 44, n. 1, p. 175-201, 2005. 
Paula Sandrin

BLOCKMANS, Steven. Participation of Turkey in the EU's Common Security and Defense Policy: Kingmaker or Trojan Horse? Leuven Center for Global Governance Studies and Centre for the Law of EU External Relations, Working Paper 41, mar. 2010.

BOOTH, Ken. Strategy and Ethnocentrism. Londres: Croom Helm, 1979.

BUZAN, Barry; DIEZ, Thomas. The European Union and Turkey. Survival, v. 41, n. 1, p. 41-57, 1999.

CAMERON: UK Working on "No-Fly Zone" Plan for Libya. BBC News, 28 fev. 2011. Disponível em: <http://www.bbc.co.uk/news/uk-politics12598674>. Acesso em: 9 nov. 2012.

CAMPBELL, David. Writing Security. United States Foreign Policy and the Politics of Identity. Minneapolis: University of Minnesota Press, 1998.

CASERT, Raf. EU Treads Carefully on Libya No-Fly Zone. The Washington Post, 9 mar. 2011. Disponível em: <http://www.washingtonpost.com/wp-dyn/content/article/2011/03/09/AR2011030900926.html>. Acesso em: 9 nov. 2012.

COMISSÃO EUROPEIA. Turkey 2013 Progress Report. 2013. Disponível em: <http://ec.europa.eu/enlargement/pdf/key_documents/2013/package/brochures/turkey_2013.pdf>. Acesso em: 4 ago. 2014.

COMISSÃO INDEPENDENTE SOBRE A TURQUIA (2009). Turkey in Europe - Breaking the Vicious Circle, 2009. Disponível em: $<$ http://www.independentcommissiononturkey.org/pdfs/2009_english.pdf >. Acesso em: 23 jan. 2012.

CONSELHO DA UNIÃO EUROPEIA. Declaration by the High Representative, Catherine Ashton, on Behalf of the European Union on Events in Libya. Bruxelas, 20 fev. 2011a. Disponível em: <http://www.consilium.europa.eu/uedocs/cms_data/docs/pressdata/en/cfsp/119397.pdf>. Acesso em: 9 nov. 2011.

Council Decision 2011/137/CFSP of 28 February 2011 Concerning Restrictive Measures in View of the Situation in Libya. Bruxelas, 28 ago. 2011b. Disponível em: <http://eur-lex.europa.eu/LexUriServ/LexUriServ.do?uri=OJ:L:2011:058:0053:0062:EN:PDF>. Acesso em: 9 nov. 2012. 
Fazendo ou Desfazendo a União Europeia enquanto Potência Global: Uma Análise...

Extraordinary European Council 11 March 2011 Declaration. Bruxelas, 20 abr. 2011c. Disponível em: <http://www.consilium.europa.eu/uedocs/cms_data/docs/pressdata/en/ec/119780.pdf>. Acesso em: 9 nov. 2012.

CONSELHO DE SEGURANÇA DAS NAÇÕES UNIDAS. Security Council Approves "No-Fly Zone" over Libya, Authorizing “All Necessary Measures" to Protect Civilians, by Vote of 10 in Favour with 5 Abstentions. 17 mar. 2011. Disponível em: <http://www.un.org/News/Press/docs/2011/ sc10200.doc.htm\#Resolution>. Acesso em: 9 nov. 2012.

CONSElHO EUROPEU. EU Council Declaration on its Southern Neighbourhood and Libya. Bruxelas, 11 mar. 2011. Disponível em: <http://www.eu-un.europa.eu/articles/fr/article_10799_fr.htm>. Acesso em: 9 nov. 2012.

DAVUTOGLU, Ahmet. Turkish Foreign Policy and the EU in 2010. Hurriyet Daily News, 10 fev. 2010. Disponível em: <http://www.hurriyetdailynew s.com/n.ph p?n=turkish-foreign-policy-and-the-eu-in2010-i-2010-02-10>. Acesso em: 12 fev. 2010.

DESAI, Seiju. Turkey and the European Union: A Security Perspective: Risk or Opportunity? Defense Studies, v. 5, n. 3, p. 366-393, 2005.

DIEZ, Thomas. Constructing the Self and Changing Others: Reconsidering "Normative Power Europe". Millennium - Journal of International Studies, v. 33, p. 613-636, 2005.

DUFFIELD, John S. Political Culture and State Behavior: Why Germany Confounds Neorealism. International Organization, v. 53, n. 4, p. 765-803, 1999.

EDWARDS, Geoffrey. The Construction of Ambiguity and the Limits of Attraction: European and its Neighborhood Policy. In: JONES, E.; VAN GENUGTEN, S. (Org.). The Future of European Foreign Policy. Abington: Routledge, 2009.

ERDOGAN, Obama Agree Gaddafi Must Step Down, Depart Libya. Today's Zaman, 27 abr. 2011. p. 4.

ERLANGER, Steven. Confusion over who Leads Libya Strikes, and for how Long. New York Times, 21 mar. 2011. Disponível em: <http://www.nytimes.com/2011/03/22/world/africa/22nato.html>. Acesso em: 9 nov. 2012. 
Paula Sandrin

FISCHER Joins Criticism of German Security Council Abstention. Spiegel Online, 22 mar. 2012. Disponível em: <http://www.spiegel.de/international/germany/shame-for-the-future-of-our-government-fischer-joins-criticism-of-german-security-council-abstention-a-752542.html>. Acesso em: 9 nov. 2012.

FRANCE and Germany Clash over Libya No-Fly Zone. Euractiv, 15 mar. 2011. Disponível em: <http://www.euractiv.com/global-europe/france-germany-clash-libya-fly-z-news-503090>. Acesso em: 9 nov. 2012.

GADDAFI Must Go - There's no Question. Spiegel Online, 21 mar. 2011. Disponível em: <http://www.spiegel.de/international/germany/spiegel-interviewwith-german-foreign-minister-gadhafi-must-go-there-s-no-questiona-752164.html>. Acesso em: 9 nov. 2012.

GARIUP, Monica. European Security Culture: Language, Theory, Policy. Farnham: Ashgate, 2009.

GRAY, Colin. Nuclear Strategy and National Style. Lanham: Hamilton Press, 1986.

Strategic Culture as Context: The First Generation of Theory Strikes Back. Review of International Studies, v. 25, n. 1, p. 49-69, 1999.

Out of the Wilderness: Prime Time for Strategic Culture. Comparative Strategy, v. 26, n. 1, p. 1-20, 2007.

GUILD, E.; BIGO, D. The Transformation of European Border Controls. In: RYAN, B.; MITSILEGAS, V. Extraterritorial Immigration Control: Legal Challenges. Leiden: Martinus Nijhoff, 2010.

HANSEN, Lene. Security as Practice: Discourse Analysis and the Bosnian War. Londres: Routledge, 2006.

HERD, Graeme P. EU-Turkey Clashing Political and Strategic Cultures as Stumbling Blocks on the Road to Accession? In: VOLTEN, P. M. E. (Org.). Perceptions and Misperceptions in the EU and Turkey - Stumbling Blocks on the Road to Accession. Centre for European Security Studies (CESS): Harmonie Paper 23, p. 47-68, 2009.

HOPF, Ted. Social Construction of International Politics - Identities and Foreign Policies - Moscow 1955 and 1999. Londres: Cornell University Press, 2002 . 
Fazendo ou Desfazendo a União Europeia enquanto Potência Global: Uma Análise...

HOWORTH, Jolyon. The CESDP and the Forging of a European Security Culture. Politique Européenne, n. 8, p. 88-108, 2002.

TURKISH Base to Be Center of NATO Operations in Libya. Hurriyet Daily News, 25 mar. 2011. Disponível em: http://www.hurriyetdailynews.com/default.aspx?pageid=438\&n=from-opposition-to-assuming-critical-role-in-libya-mission-2011-03-25. Acesso em: 9 nov. 2012.

HUYSMANS, J. The Politics of Insecurity: Fear, Migration and Asylum in the EU. Londres: Routledge, 2006.

IDIZ, Semih. Erdogan Misreads Libyan Sanctions. Hurriyet Daily News, 28 fev. 2011. Disponível em: <http://www.hurriyetdailynews.com/n.php?n=erdogan-misreads-libyan-sanctions-2011-02-28>. Acesso em: 16 ago. 2011.

JOHNSTON, Alastair Iain. Cultural Realism and Strategy in Maoist China. In: KATZENSTEIN, P. J. (Org.). The Culture of National Security: Norms and Identity in World Politics. Nova York: Columbia University Press, 1996.

Strategic Cultures Revisited: Reply to Colin Gray. Review of International Studies, v. 25, n. 3, p. $519-523,1999$.

KALIN, Ibrahim. Turkish Foreign Policy in 2011: An Assessment. In: BECHEV, D. (Org.). What does Turkey Think. European Council on Foreign Relations, jun. 2011.

KART, Emine. Turkey's Cease-Fire Priority in Libya Gaining Currency in NATO. Today's Zaman, 19 abr. 2011, p. 4.

KIRCHNER, Emil. European Union; Moving towards a European Security Culture? In: KIRCHNER, E.; SPERLING, J. (Org.). National Security Cultures - Patterns of Global Governance. Londres: Routledge, 2010.

__ SPERLING, James (Org). National Security Cultures - Patterns of Global Governance. Londres: Routledge, 2010.

KIRKPATRICK, David; ERLANGER, Steven; BUMILLER, Elisabeth. Allies Open Air Assault on Qaddafi's Forces in Libya. New York Times, 19 mar. 2011. Disponível em: <http://www.nytimes.com/2011/03/20/world/africa/20libya.html?pagewanted=1\&_r=2\&hp>. Acesso em: 9 nov. 2012.

KOENIG, Nicole. The EU and the Libyan Crisis: In Quest of Coherence? IAI Working Papers 11, 19 set. 2011.

KORUTURK, Osman. The CHP Delegation Aims to Introduce the Party's Vision of a "New Turkey", 2011. Disponível em: <http://www.chp. 
Paula Sandrin

org.tr/en/? manset=koruturk-the-chp-delegation-aims-to-introducethe-partys-vision-of-a-new-turkey>. Acesso em: 28 jan. 2013.

KRAUSE, Keith. Cross-Cultural Dimension of Multilateral Non-Proliferation and Arms Control Dialogues: An Overview. In: KRAUSE, K. (Org.). Culture and Security: Multilateralism, Arms Control and Security Building. Londres: Frank Class, 1999.

LANTIS, Jeffrey S. Strategic Culture and National Security Policy. International Studies Review, v. 4, n. 3, p. 87-113, 2002.

LAPID, Yosef. Culture's Ship: Returns and Departures in International Relations Theory. In: LAPID, Y.; KRATOCHWIL, F. The Return of Culture and Identity in IR Theory. Londres: Lynne Rienner Publishers, 1996.

LÉONARD, Sarah. EU Border Security and Migration into the European Union: FRONTEX and Securitisation through Practices. European Security, v. 19, n. 2, p. 231-254, 2010.

LIBYA: UK and French No-Fly Zone Plan Gathers Pace. BBC News, 8 mar. 2011a. Disponível em: <http://www.bbc.co.uk/news/world-africa12672640>. Acesso em: 9 nov. 2012.

LIBYA: UK Forces Prepare after UN No-Fly Zone Vote. BBC News, 18 mar. 2011b. Disponível em: <http://www.bbc.co.uk/news/uk-politics-12770467>. Acesso em: 9 nov. 2012.

MANNERS, Ian. Normative Power Europe Reconsidered: Beyond the Crossroads. Journal of European Public Policy, v. 13, n. 2, p. 182-199, 2006.

MEYER, Christopher. The Quest for a European Strategic Culture - Changing Norms on Security and Defense in the European Union. Basingstoke: Palgrave Macmillan, 2006.

MÜFTÜLER-BAÇ, Meltem. The European Union's Accession Negotiations with Turkey from a Foreign Policy Perspective. In: JONES, E.; VAN GENUGTEN, S. (Org.). The Future of European Foreign Policy. Abington: Routledge, 2009.

MURISON, Alexander. The Strategic Depth Doctrine of Turkish Foreign Policy. Middle Easter Studies, v. 42, n. 6, p. 945-964, 2006.

NEAL, A. Securitization and Risk at the EU Border: The Origins of FRONTEX. Journal of Common Market Studies, v. 47, n. 2, p. 333-356, 2009.

Uses of the Other - "The East” in European Identity Formation. Minneapolis: University of Minnesota Press, 1999. 
Fazendo ou Desfazendo a União Europeia enquanto Potência Global: Uma Análise...

NEUMANN, Iver B.; HEIKKA, Henrikk. Grand Strategy, Strategic Culture and Practice: The Social Roots of Nordic Defense. Cooperation and Conflict, v. 40, n. 5 , p. $5-23,2005$.

OGUZLU, Tarik H. Turkey and the European Union - The Security Dimension. Contemporary Security Policy, v. 23, n. 3, p. 61-82, 2002.

; KIBAROGLU. Incompatibilities in Turkish and European Security Cultures Diminish Turkey's Prospects for EU Membership. Middle Eastern Studies, v. 44, n. 6, p. 945-962, 2008.

OZCAN, Mesut. Harmonizing Foreign Policy - Turkey, the EU and the Middle East. Aldershot: Ashgate, 2008.

OZERKAN, Fulya. Davutoglu Delights Libyans in Benghazi’s Tahrir Square. Hurriyet Daily News, 4 jul. 2011. Disponível em: <http://www.hurriyetdailynews.com/n.php?n=davutoglu-delights-libyans-in-benghazi8217s-tahrirsquare-2011-07-04>. Acesso em: 16 ago. 2011.

PHILIPS, Leigh. UN Says EU Soldiers Could Endanger Aid Workers. EU Observer, 21 abr. 2011. Disponível em: <http://euobserver.com/24/32224>. Acesso em: 29 out. 2011.

POLAT, Rabia Karakaya. How Far away from the Politics of Fear: Turkey in the EU Accession Process. In: TUNKROVA, L.; SARADIN, P. (Org.). The Politics of EU Accession: Turkish Challenges and Central European Experiences. Londres: Routledge, 2010.

RETTMAN, Andrew. France: Libya War Marks New Chapter in EU-US Relations. EU Observer, $1^{\circ}$ set. 2011. Disponível em: <http://euobserver.com/ 13/113486>. Acesso em: 18 set. 2011.

RUACAN, Ipek. A Study in State Socialization: Turkey's EU Accession and CFSP. Southeast European and Black Sea Studies, v. 7, n. 4, p. 573-590, 2007.

SNYDER, Jack. The Soviet Strategic Culture: Implications for Limited Nuclear Operations. Santa Monica: RAND, 1977.

TRAYNOR, Ian. Libya No-Fly Zone Plan Rejected by EU Leaders. The Guardian, 11 mar. 2011. Disponível em: <http://www.guardian.co.uk/world/2011/ mar/11/libya-no-fly-zone-plan-rejected>. Acesso em: 9 nov. 2012.

TURKEY Criticizes France's Role in Libya Intervention. Today's Zaman, 22 mar. 2011. Disponível em: <http://www.todayszaman.com/news-238853-turkey-criticizes-frances-role-in-libya-intervention.html>. Acesso em: 9 nov. 2012. 
USTUN, Cigdem. Turkey and European Security Defence Policy: Compatibility and Security Cultures in a Globalised World. Londres: I. B. Tauris, 2010.

WAEVER, Ole. Securitization and Desecuritization. In: LIPSCHUTZ, R. D. (Org.). On Security. Nova York: Columbia University Press, 1995.

Identity, Communities and Foreign Policy - Discourse Analysis as Foreign Policy Theory. In: HANSEN, L.; WAEVER, Ole. European Integration and National Identity: The Challenge of the Nordic States. Londres: Routledge, 2001 .

WATT, Nicholas; HOPKINS, Nick; TRAYNOR, Ian. Nato to Take Control in Libya after US, UK, and France Reach Agreement. The Guardian, 23 mar. 2011. Disponível em: <http://www.guardian.co.uk/world/2011/mar/22/libyanato-us-france-uk>. Acesso em: 9 nov. 2012.

WELDES, Jutta; LAFFEY, Mark; GUSTERSON, Hugh; DUVALL, Raymond (Org.). Cultures of Insecurities. States, Communities, and the Production of Danger. Minneapolis: University of Minnesota Press, 1999.

YINANÇ, Barçin. Defending a Bloody Dictator from Christian Crusades. Hurriyet Daily News, 22 mar. 2011. Disponível em: <http://www.hurriyetdailynews.com/n.php?n=defending-a-bloody-dictator-8220from-christian-crusades8221-2011-03-22>. Acesso em: 16 ago. 2011.

\section{Resumo}

\section{Fazendo ou Desfazendo a União Europeia enquanto Potência Global: Uma Análise sobre Potenciais Impactos da Turquia na Política Externa e de Segurança Comum do Bloco}

Este artigo tem como objetivo desafiar a lógica binária que permeia a discussão sobre o impacto da adesão da Turquia na política externa e de segurança comum (PESC) da União Europeia (UE). Defende-se que qualquer análise sobre tal impacto precisa levar em consideração as divisões existentes dentro da Europa e dentro da Turquia em termos de culturas de segurança. Com o intuito de ilustrar a pluralidade de culturas de segurança existentes na UE e na Turquia e fornecer indicações sobre as potenciais contribui- 
Fazendo ou Desfazendo a União Europeia enquanto Potência Global: Uma Análise...

ções do país para a Europa enquanto ator internacional, são analisadas as respostas da União Europeia como um bloco, de alguns países-membros europeus (França, Reino Unido e Alemanha) e da Turquia ao conflito na Líbia em 2011. Conclui-se que, com ou sem a Turquia, a União Europeia deverá continuar a atuar como uma potência humanitária no cenário mundial e que, portanto, os potenciais impactos de uma eventual adesão turca não devem ser exagerados.

Palavras-chave: União Europeia - Política Externa e de Segurança Comum - Turquia - Cultura de Segurança

\section{Abstract}

\section{Making or Breaking the European Union as a Global Power: An Analysis of the Potential Impacts of Turkish Membership on the EU's Common Foreign and Security Policy}

This article aims to challenge the binary logic that pervades discussions about the impact of Turkish membership on the European Union's Common Foreign and Security Policy (CFSP). It argues that any assessment of such impact must take into account existing divisions within Europe and within Turkey in terms of security culture. In order to illustrate the plurality of security cultures existent within the European Union and within Turkey and to understand the country's potential contributions to Europe as an international actor, an analysis of the EU's, some member states' and Turkey's responses to the conflict in Libya in 2011 will be provided. It will conclude that Turkey's impact on the EU's role in the world should not be overestimated. The EU is likely to continue to resemble a Humanitarian Power in the world stage, with or without Turkey.

Keywords: European Union - Common Foreign and Security Policy Turkey - Security Culture 